\title{
Severe Asthma Management, Patient Pathway, and Disease Burden in Russia: Country Results From Multi-Country Retrospective Cross-Sectional Study
}

\section{Zaurbek Aisanov}

Federal Pulmonology Research Institute

Oksana Kurbacheva

Institute of Immunology

Alexander Emelyanov

North-Western Medical University

Galina Ignatova

Institute of Additional Professional Education of the Southern State Medical University

Lindsey Teichman

GlaxoSmithKline

Janina Makarova ( $\square$ yana.j.makarova@gsk.com )

GlaxoSmithKline

\section{Sergey Fedosenko}

Federal State Budgetary Educational Institution of Higher Education "Siberian State Medical University" of the Ministry of Health of the Russian Federation

\section{Rafael Alfonso}

GlaxoSmithKline

\section{Tamer Elfishawy}

GlaxoSmithKline

\section{Research Article}

Keywords: severe asthma, eosinophil levels, Russia, Asthma Control Test (ACT), HRQoL questionnaire

Posted Date: November 12th, 2021

DOI: https://doi.org/10.21203/rs.3.rs-1027666/v1

License: (c) (1) This work is licensed under a Creative Commons Attribution 4.0 International License.

Read Full License 


\section{Abstract \\ Background}

Severe asthma is a poorly controlled disease in Russia which leads to significant healthcare resource use and costs. However, little is known about its burden and management in a real clinical practice in Russia. Here we report the results obtained in the Russian population during an international cross-sectional study.

\section{Methods}

The study comprised two phases: in Phase I data were collected retrospectively from medical records, while Phase II was a cross-sectional collection of patient-reported outcomes and up-to-date data. For Phase I, adult patients with severe asthma according to ERS/ATS criteria were enrolled. Phase I patients were enrolled into Phase II if they signed a written consent form. Data on demographics, history of asthma and comorbidities, treatment approach, and healthcare resource utilization were obtained in both phases. In Phase II, asthma control and health-related quality of life (HRQoL) were also evaluated.

\section{Results}

A total of 315 patients were included in Phase I of the study, 106 (33.6\%) of them entered Phase II of the study. The study population included more female $(n=211,67.0 \%)$ than male patients $(n=104,33.0 \%)$. Majority of subjects were either obese $(n=103,39.8 \%)$ or overweight $(n=94,36.3 \%)$. The most common comorbidity was cardiovascular disease $(n=217,71.4 \%)$, followed by chronic respiratory disease $(n=198$, $68.8 \%$ ), including COPD and allergies. Mean (SD) age at diagnosis of asthma and severe asthma were 42.9 (16.0) and 53.1 (13.2) years, respectively. There were 268 (85.1\%) patients who had at least one exacerbation during last 12 months. Most subjects had only one blood eosinophil count in the last 12 months ( $n=143,81.3 \%$ ). Mean (SD) FEV1 was 56.9 (20.4) \% predicted. The mean (SD) last serum $\mathrm{lgE} /($ RAST) value was 254.3 (249.7) $\mathrm{ng} / \mathrm{mL}$. Asthma management was generally in line with guidelines. Most patients had poorly controlled asthma according to the ACT and impaired HRQoL.

\section{Conclusions}

In Russia, severe asthma patients had poor disease control, high hospital admission rates and multiple comorbidities. Eosinophil and IgE level measurements are not considered routine tests which might be a barrier for appropriate phenotyping and treatment selection, including prescription of biologics in course of disease management.

\section{Background}


Many patients with asthma can be adequately controlled by use of treatment recommendations as described by the Global Initiative for Asthma (GINA) guidelines (1). However, for some asthma patients, despite attempts to control their disease following these recommendations, asthma control is not achieved. Landmark studies have shown that uncontrolled asthma remains a worldwide problem (2). This group of subjects with frequent exacerbations, uncontrolled symptoms and impaired health-related quality of life (HRQoL) has been defined as severe asthma patients (3). Severe asthma has been defined by the American Thoracic Society (ATS) and the European Respiratory Society (ERS) as "asthma which requires treatment with high dose inhaled corticosteroids (ICS) plus a second controller (and/or systemic corticosteroids [SCS]) to prevent it from becoming 'uncontrolled' or which remains 'uncontrolled' despite this therapy" (4). Severe asthma patients experience considerable morbidity (5) and are responsible for approximately $50 \%$ of the total health costs associated with asthma $(6,7)$.

Evidence shows that patients with severe asthma are comprised of complex, overlapping phenotypes, including severe eosinophilic asthma $(8,9)$. Early identification of patients with eosinophilic asthma in clinical practice is important because these patients are at risk of poor asthma outcomes (10). For these reasons, there is a need to assess severe asthma management and the patient care depending on asthma phenotypes. However, little is known about the burden and management of severe asthma patients in real clinical practice in Russia, and it is unclear what asthma phenotypes are present in those with severe asthma in Russia. Thus, the primary objective of this study was to describe the patient care pathway, disease management and patient/disease characteristics, including patient demographics, clinical characteristics, and healthcare resource use in severe asthma patients.

\section{Methods}

\section{Study design}

This study was an observational, descriptive, retrospective cross-sectional conducted in Russia, Saudi Arabia, Kuwait, and the United Arab Emirates. This manuscript focuses on the Russian population. The study consisted of two phases. At Phase I retrospective data on severe asthma patients was collected. Investigators from 12 sites in Russia screened site medical records dated from 01 January 2016 until site initiation visit (SIV, start at 31 May 2018, finish on 10 August 2018). Any patients aged 21 years or older with severe asthma diagnosis according to ERS/ATS definition have been included in the registry. Known participants of a clinical or cohort study were ineligible. The number of patients to be enrolled was not limited. Medical records of eligible patients were reviewed by investigators for extraction of data including, but not limited to clinical data, disease and treatment history, laboratory tests, including eosinophil and immunoglobulin E (IgE) level measurements, spirometry results during 12 months prior to SIV, number of exacerbations, and number of hospital admissions.

Asthma exacerbation was defined as an event that required use of systemic corticosteroids (SCS) or led to hospital admission, emergency room (ER) visit, mechanical ventilation, or doubling the oral corticosteroids (OCS) dose for patients receiving maintenance OCS. 
Eligible patients enrolled in Phase I of the study, and who presented at the site for a routine visit, were invited to participate in Phase II of the study. Patients who refused to sign informed consent, or who presented a severe mental illness or other disease that could, in an investigator's opinion, alter participation in the study, were ineligible. The recruitment period for Phase I and II lasted 14 weeks. Participants were asked to complete the Asthma Control Test (ACT) and the Five level EuroQol fivedimension (EQ-5D-5L) HRQoL questionnaires. Investigators also extracted relevant data from the medical records, as done during Phase I.

\section{Statistical analysis}

Data were analyzed using descriptive statistics. Categorical and ordinal variables are presented as frequency and counts. Continuous variables are presented as mean values with standard deviation (SD). Analyses conducted to meet the primary objective (to describe the patient pathway, in terms of disease management and patient/disease characteristics) were also stratified by the last available eosinophil count. Analyses conducted to meet the secondary objectives (to describe the burden of severe asthma in terms of healthcare resource utilisation, impact of disease on HRQoL for overall, controlled, and uncontrolled severe asthma patients in specialised sites) involved frequencies, and two-tailed $95 \%$ confidence intervals (Cls) were presented for selected variables.

Categorical variables were compared using chi-square test, Student's t-test or analysis of variance (ANOVA) were used for continuous variables. Two-sided significance level of 0.05 was accepted for all statistical tests.

All statistical analyses were performed using SAS 9.4 (SAS Institute, North Carolina, USA) software.

\section{Results}

\section{Study population}

Patient disposition is presented at Figure 1. A total of 392 patients screened for Phase I, 315 were enrolled, and 77 were excluded as ineligible. Of 315 patients, 106 visited sites during the enrollment period and gave consent for study participation.

Characteristics of patients included in the study are presented in Table 1. There were numerically more female $(n=211,67.0 \%)$ than male patients $(n=104,33.0 \%)$ in the study. Majority of patients were older than 50 years. Most enrolled patients were Caucasians $(n=257,84.3 \%)$ and were either obese with a body mass index $(\mathrm{BMI}) \geq 30 \mathrm{~kg} / \mathrm{m}^{2}(\mathrm{n}=103,39.8 \%)$ or overweight with a BMI between 25 and $<30 \mathrm{~kg} / \mathrm{m}^{2}$ $(n=94,36.3 \%)$. More than half of the patients were non-smokers $(n=193,64.5 \%)$; the remaining patients were either past smokers ( $n=66,22.1 \%)$, current smokers $(n=38,12.7 \%)$, or passive smokers $(n=2,0.7 \%)$. Among the current and past smokers, the mean (SD) number of cigarettes smoked per day was 17.7 (7.9), and the mean (SD) pack-years was 25.4 (17.7). The overall mean (SD) number of years as a smoker among past and current smokers was 27.7 (12.6) years. 
Table 1

Summary sociodemographic data for patients who entered Phases I and II

\begin{tabular}{|c|c|}
\hline Parameter & Study population from Russia $(n=315)$ \\
\hline Sex, n (\%) & $211(67.0)$ \\
\hline Female & $104(33.0)$ \\
\hline \multicolumn{2}{|l|}{ Male } \\
\hline Age at entry, median (range) & $60.0(24.0-83.0)$ \\
\hline BMI, n (\%) & $2(0.8)$ \\
\hline Underweight $(\mathrm{BMI}<18.5$ kg/m²) & $60(23.2)$ \\
\hline Normal weight $\left(18.5 \leq \mathrm{BMI}<25 \mathrm{~kg} / \mathrm{m}^{2}\right)$ & $94(36.3)$ \\
\hline Overweight $\left(25 \leq \mathrm{BMl}<30 \mathrm{~kg} / \mathrm{m}^{2}\right)$ & $103(39.8)$ \\
\hline Obese $\left(\mathrm{BMI} \geq 30 \mathrm{~kg} / \mathrm{m}^{2}\right)$ & 56 \\
\hline \multicolumn{2}{|l|}{ Missing } \\
\hline Height, cm median (range) & $164.0(140.0-195.0)$ \\
\hline Ethnicity, n (\%) & $257(84.3)$ \\
\hline Caucasian & $5(1.6)$ \\
\hline Asian & $43(14.1)$ \\
\hline Other & 10 \\
\hline \multicolumn{2}{|l|}{ Unknown/missing } \\
\hline Education, $\mathrm{n}(\%)$ & $12(7.6)$ \\
\hline Some high school & $26(16.5)$ \\
\hline High school graduate & $22(13.9)$ \\
\hline Technical postsecondary & $66(41.8)$ \\
\hline Some college & $29(18.4)$ \\
\hline College graduate & $3(1.9)$ \\
\hline Post graduate degree & 157 \\
\hline Unknown/missing & \\
\hline
\end{tabular}

Notes: $\mathrm{BMI}$ - body mass index; percentages in the table were calculated for available data (excluding unknown/missing). 


\section{Parameter}

\section{Employment status, $\mathbf{n}(\%)$}

Employed full or part time

Homemaker

Unemployed/Retired

Disabled or too ill to work

Unknown/missing

Household income, n (\%)

Less than minimum wage

Minimum wage

$2 \mathrm{x}$ minimum wage

More than $2 \times$ minimum wage

Unknown/missing

Smoking status, $\mathrm{n}(\%)$

Current smoker

Past-smoker

Non-smoker

Passive smoking at home/other

Unknown/missing

\section{Study population from Russia $(n=315)$}

$83(29.6)$

9 (3.2)

$145(51.8)$

$43(15.4)$

35

6 (5.7)

59 (56.2)

24 (22.9)

16 (15.2)

210

38 (12.7)

66 (22.1)

193 (64.5)

2 (0.7)

16

Notes: $\mathrm{BMI}$ - body mass index; percentages in the table were calculated for available data (excluding unknown/missing).

\section{Medical history}

Among the 315 patients enrolled in Phase I, 303 (96.2\%) patients had at least one comorbidity. Overall, the mean (SD) number of all comorbidities, disease comorbidities, allergic conditions, and other comorbidities were $3.0(1.4), 2.2(1.0), 1.8(0.8)$, and $1.0(1.0)$, respectively. The most common comorbidity was cardiovascular disease $(n=217,71.4 \%)$, followed by chronic respiratory disease $(n=198$, $68.8 \%$ ) (including chronic obstructive pulmonary disease [COPD, $n=99,31.5 \%$ ], allergic rhinitis [n=94, $30.4 \%]$, or other $[n=62,20.9 \%])$, respiratory allergies $(n=64,22.6 \%)$, drug allergies $(n=57,21.3 \%)$, gastrointestinal disease $(n=55,19.3 \%)$, and other allergies $(n=36,12.7 \%)$. Renal disease, rheumatological disease, diabetes with/without end-organ damage, malignancy disease, immunological disease, and food allergies were each reported in less than $10 \%$ of the patients. There were nine other comorbidities also reported, including obesity, osteochondrosis, benign prostatic hyperplasia, iron deficiency anemia, 
dyslipidemia, gout, hyperlipidemia, osteoarthritis, and sinusitis; 56 (57.1\%) patients had other comorbidities.

Asthma history data is presented in Table 2. Among the 315 patients, the median (range) age at diagnosis of asthma or severe asthma was 45.0 (1.0-79.0) and 55.5 (15.0-82.0) years, respectively. The median (range) age at the first symptoms of asthma was 42.0 (1.0-76.0) years. The mean (SD) time between asthma diagnosis and severe asthma diagnosis was 10.1 (11.1) years. Most patients did not have a familial first-degree history of asthma $(n=150,62.0 \%)$. 
Table 2

Asthma medical history

\begin{tabular}{|c|c|}
\hline Parameter & $\begin{array}{l}\text { Study population from } \\
\text { Russia }(n=315)\end{array}$ \\
\hline Age at diagnosis, years median (range) & $45.0(1.0-79.0)$ \\
\hline Age at first symptoms of asthma, years median (range) & $42.0(1.0-76.0)$ \\
\hline Age at diagnosis of severe asthma, years median (range) & $55.5(15.0-82.0)$ \\
\hline Years since diagnosis of severe asthma median (range) & $3.0(0.0-43.0)$ \\
\hline Familial first-degree history of asthma, $n(\%)$ & $92(38.0 \%)$ \\
\hline Yes & $150(62.0 \%)$ \\
\hline No & 73 \\
\hline \multicolumn{2}{|l|}{ Missing } \\
\hline $\begin{array}{l}\text { Number of physicians that were seen before being diagnosed with } \\
\text { severe asthma median (range) }\end{array}$ & $2.0(1.0-10.0)$ \\
\hline \multirow[t]{2}{*}{$\begin{array}{l}\text { Medical specialty of the physician that has diagnosed severe asthma, } \\
\mathrm{n}(\%)\end{array}$} & $19(6.7 \%)$ \\
\hline & $189(66.5 \%)$ \\
\hline General/Family Practice & $75(26.4 \%)$ \\
\hline Respiratory specialist & $1(0.4 \%)$ \\
\hline \multicolumn{2}{|l|}{ Cardiologist } \\
\hline \multicolumn{2}{|l|}{ Missing } \\
\hline \multirow{2}{*}{$\begin{array}{l}\text { Medical specialty of the physician seen most often by patient for } \\
\text { severe asthma follow-up, } n(\%)\end{array}$} & $98(32.7 \%)$ \\
\hline & $161(53.7 \%)$ \\
\hline General/Family Practice & $41(13.7 \%)$ \\
\hline Respiratory specialist & 15 \\
\hline \multicolumn{2}{|l|}{ Allergist } \\
\hline \multicolumn{2}{|l|}{ Missing } \\
\hline Routine follow-up for severe asthma, $n$ (\%) & $279(94.9 \%)$ \\
\hline Yes & $15(5.1 \%)$ \\
\hline No & 21 \\
\hline Missing & \\
\hline
\end{tabular}


The most reported frequencies of nighttime awakenings due to severe asthma in the last 12 months were once a week $(n=55,23.9 \%)$, twice a week $(n=40,17.4 \%)$, and once per fortnight $(n=39,17.0 \%)$ (Figure 2$)$.

There were 268 (85.1\%) patients who experienced at least one asthma exacerbation during the last 12 months, the majority of them had 1 exacerbation during the past 12 months ( $n=209,66.3 \%$ ) (Figure 3). Exacerbations were most common during spring $(n=116,36.8 \%)$, followed by winter $(n=91,28.9 \%)$, summer $(n=70,22.2 \%)$, and autumn $(n=54,17.1 \%)$. The mean (SD) duration of exacerbation was $8.5(5.3)$ days. For most patients, flu or common cold was the trigger for exacerbation ( $n=135,46.2 \%)$.

\section{Laboratory data}

A total of 176 patients had blood eosinophil counts data available in either Phase I or II, one measurement data was available for the majority of patients $(n=159,82.0 \%)$. Therefore, eosinophil count control is not frequently used in routine practice. The highest mean (SD) eosinophil level observed was 123.9 (173.2) cells/ $\mu \mathrm{L}$. Among the 106 patients enrolled in Phase II of the study, 4 (3.8\%) patients had a blood eosinophil count recorded at visit. Mean (SD) blood eosinophil count was 46.5 (86.4) cells/ $\mu \mathrm{L}$.

Data on IgE measurements were available for 88 patients, nearly all patients had only one test performed in the 12 months prior to data entry in Phase I $(n=82,93.2 \%)$. The mean (SD) last serum IgE value was $254.3(249.7) \mathrm{ng} / \mathrm{mL}$. Therefore, most patients' last serum IgE value was $\leq 244 \mathrm{ng} / \mathrm{mL}$, which is considered normal $(n=52,59.8 \%)$.

Retrospective spirometry data are shown in Figure 4.

Note FEV1 - forced expiratory volume in first second; last FVC - forced vital capacity; data represent mean for 279 patients.

Among the 279 patients with available data on lung function examinations in the last 12 months, the majority had only one lung function examination ( $n=202,72.4 \%)$. The mean (SD) last forced expiratory volume in first second (FEV1), last forced vital capacity (FVC), and last FEV1/FVC value were 56.9 (20.4), 76.0 (21.1), and 76.0 (18.0) \% of predicted, respectively. Overall, most patients had a last FEV1/FVC value between $50 \%$ and $70 \%(n=230,93.9 \%)$.

No IgE evaluations were recorded in cross-sectional part of study. Spirometry data was available for 29 patients included in Phase II. The mean (SD) FEV1 value was 56.6 (21.7) \% of predicted, and most patients had a FEV1 value of $>50 \%(n=16,55.2 \%)$. There were 15 patients with a FVC value recorded at the cross-sectional visit. The mean (SD) FVC value was 80.9 (18.3) \% predicted, and most patients had a FVC value of $>70 \%(n=10,66.7 \%)$. The mean (SD) FEV-1/FVC ratio was $72.3(19.4) \%$ predicted $(n=15)$.

\section{Disease management}

Asthma treatment related data are shown in Table 3. Among the 315 patients, the most common treatment prescribed in the last 12 months was controller/maintenance treatment $(n=313,99.4 \%)$, followed by reliever treatment $(n=305,96.8 \%)$, exacerbation treatments (short-acting $\beta$-agonists [SABA] 
excluded) ( $n=249,79.0 \%)$, and other medication ( $n=245,77.8 \%)$. In terms of the distinct number of medications prescribed for each category, exacerbation treatments (SABA excluded) had the highest mean (SD) number during the last 12 months (4.3 [3.2]), followed by other drugs (3.2 [2.3]), controller/maintenance treatment (1.9 [0.9]), and reliever treatments (1.1 [0.4]). New or ongoing reliever treatments had the longest mean (SD) treatment duration (11.1 [2.6] months), followed by controller/maintenance treatments (9.9 [3.3] months), other medications (8.0 [4.2] months), and exacerbation treatments (SABA excluded) (1.0 [2.2] months).

Table 3

Treatments prescribed and average duration of treatment use for severe asthma

\section{Parameter}

Study population from Russia $(n=315)$

Number of distinct controller/maintenance treatments prescribed for severe asthma in the last 12 months median (range)

$1.9(0.9)$

Number of distinct reliever treatments for severe asthma prescribed in the last 12 months, mean (SD)

$1.1(0.4)$

Number of distinct exacerbation treatments for severe asthma prescribed in the last 12 months, mean (SD)*

$4.3(3.2)$

Number of distinct other medications prescribed in the last 12 months, mean $(\mathrm{SD})$

$3.2(2.3)$

Average duration of any new or ongoing controller/maintenance treatments for severe asthma in the last 12 months, months, mean (SD)

$9.9(3.3)$

Average duration of any new or ongoing exacerbation treatments for severe asthma in the last 12 months, months, mean (SD) *

$1.0(2.2)$

Average duration of any new or ongoing other medications in the last 12 months, months, mean (SD)

$8.0(4.2)$

Note: SABA - short-acting $\beta$-agonist; * - excluding SABA; SD - standard deviation.

Among the 315 patients, 199 (63.2\%) patients received OCS treatment in the past 12 months. The mean (SD) overall daily dose of OCS in the last 12 months was 2.9 (5.1) $\mathrm{mg}(\mathrm{n}=199)$. The mean (SD) daily dose of OCS for controller/maintenance treatment in the last 12 months was 6.1 (4.1) $\mathrm{mg}(\mathrm{n}=16)$. The mean (SD) daily dose of OCS for exacerbation treatment in the last 12 months was 2.5 (4.9) $\mathrm{mg}(\mathrm{n}=194)$.

Among the 313 (99.4\%) patients who received controller/maintenance treatment, the most common treatments (i.e., prescribed in $>5 \%$ of patients) were medium/high dose ICS/long-acting $\beta$-agonists (LABA) $(n=291,93.0 \%)$, tiotropium bromide $(n=156,49.8 \%)$, leukotriene receptor antagonist (LTRA) $(n=28,8.9 \%)$, other $(n=19,6.1 \%)$, medium/high dose ICS $(n=18,5.8 \%)$, and low dose OCS $(n=16,5.1 \%)$. The mean (SD) days of treatment among the most common treatments ranged from 239.9 (125.3) days in LTRA to 315.8 (100.0) days in medium/high dose ICS/LABA. In 12 months prior to inclusion, the most common (i.e., observed in $>5 \%$ of patients) first prescribed controller/maintenance treatment started during the past 12 
months was medium/high dose ICS/LABA ( $n=291,92.4 \%)$, followed by tiotropium bromide ( $n=156$, $49.5 \%)$, LTRA ( $n=28,8.9 \%)$, medium/high dose ICS and other ( $n=19,6.0 \%$, for both).

Among the 305 (96.8\%) patients who received reliever treatment, the most common treatments (i.e., prescribed in $>5 \%$ of patients) were short-acting beta 2 agonists $(n=224,73.4 \%)$, followed by other treatments $(n=70,23.0 \%)$, and low dose ICS/formoterol $(n=21,6.9 \%)$. The mean (SD) treatment duration was 293.2 (133.7) days in low dose ICS/formoterol, 337.5 (78.0) days in other treatments, and 341.1 (75.1) days in SABA.

There were 250 (79.4\%) patients with prescribed exacerbation treatment during the 12 months prior to study inclusion. The most common treatments (i.e., prescribed in $>5 \%$ of patients) were systemic corticosteroid (OCS/parenteral) $(n=198,79.2 \%)$, other treatments $(n=175,70.0 \%)$, SABA (Salbutamol) $(n=24,9.6 \%)$, short-acting muscarinic antagonist (SAMA) (ipratropium) $(n=22,8.8 \%)$, and oxygen $(n=16$, $6.4 \%$ ). Among the common exacerbation treatments for severe asthma, the mean (SD) treatment duration ranged from 22.6 (30.6) days for oxygen to 60.0 (92.0) days for SABA.

Among the 250 patients who experienced at least one exacerbation within the prior 12 months, physician consultation was the most frequent intervention ( $n=227,75.4 \%)$. A total of $30(10.6 \%)$ patients experienced at least one exacerbation which required an ER visit, and $200(67.1 \%)$ were hospitalized with a mean (SD) of 12.3 (6.0) nights spent in hospital in the last 12 months.

\section{Patient-Reported Outcomes}

Questionnaires were completed by the patients who participated in Phase II $(n=106)$. Most patients had an ACT score of $\leq 15$ and fell in the category "asthma may not be under control" ( $n=79,74.5 \%)$; there were $22(20.8 \%)$ patients with an ACT score of $\geq 16$ to $\leq 19$ and fell in the category "asthma partially or not well controlled"; and 5 (4.7\%) patients with an ACT score of $\geq 20$ and fell in the category "asthma may be under control". The mean (SD) ACT score was 11.4 (4.7).

The mean (SD) EQ-5D-5L utility score was 0.5 (0.3), and the mean (SD) EQ-5D visual analogue scale (VAS) score was 51.8 (20.2). The mean (SD) number of school or workdays patients reported missing due to severe asthma was 17.6 (21.8) days. The mean (SD) number of school or workdays with less productivity due to severe asthma was 44.6 (45.2) days. Overall, higher quality of life was associated with better asthma control.

\section{Limitations}

Most of the sites selected in this study were public hospitals (hence the results show that almost all patients were covered by public/social security healthcare), and thus the generalizability of the results is limited to patients treated in public healthcare settings. Physician participation in Phase $\mathrm{I} / \mathrm{II}$ and patient participation in Phase II were on a voluntary basis; this may have resulted in selection bias, thereby impacting the representativeness of the final sample of participating physicians and patients. Missing data, which is a known disadvantage of observational studies, could reduce the statistical power of 
analyses and may potentially bias estimates. There was very limited data captured on blood eosinophil measurements in this study. Finally, it is important to consider the reliability of certain variables, e.g., smoking status may be impacted by reporting bias, due to the reluctance of patients to report smoking behavior to their doctor.

\section{Discussion}

This retrospective cross-sectional study conducted in Russia collected and analysed real-world data on patients with severe asthma, including patient care pathway, disease management and patient/disease characteristics (demographics, clinical characteristics, healthcare resource utilisation and HRQoL).

In the Russian population included in the current study, most of the patients were female, which is in line with the previously reported data on asthma epidemiology $(11,12)$. The majority of patients were aged $>50$ years. Similar was reported by the International Severe Asthma Registry (ISAR), where $52.1 \%$ were aged 55 to 69 years (12).

Previous studies have shown that other respiratory disease, such as cardiovascular disease, gastrointestinal disease, allergies and diabetes are prevalent in patients with asthma (13-15). In this study, on average, patients had approximately three comorbidities and the most common comorbidities were cardiovascular disease $(71.4 \%)$ and chronic respiratory disease (68.8\%). It is of interest to note the high proportion of patients with concomitant COPD (31.5\%) observed in this study, it is known that asthma represents a significant risk factor for COPD (16). On the other hand, there might be a high proportion of COPD patients in Russia misdiagnosed with asthma due to difficulties in differential diagnosis and/or intention to receive better therapies refunded by healthcare system. Another possible explanation for this finding is the relatively high rate of smoking in patients with severe asthma.

Median age for asthma diagnosis was 45.0 years and 55.5 for severe asthma. In a US-based survey $(n=12,216)$ the average age of asthma onset among adults was 38 years (17). Another study has shown that in asthma patients the risk of subsequent development of severe asthma increases by around $7 \%$ each year until age 45 years (18).

The majority of patients had at least one exacerbation in the last 12 months, highest exacerbation frequency was in spring, followed by winter, summer, and autumn. Seasonal peaks in asthma exacerbations are well described in the literature, with variations according to the geography and climate (19). In this study flu/cold was the major trigger for exacerbation (46.2\%), which has also been identified by the other studies (20).

Mean blood eosinophil levels remained consistently elevated over consecutive measurements. It was observed in other study that elevated eosinophils are related to poorer asthma control (21). Sites that participated in this study did not routinely record eosinophil levels, despite blood eosinophil counts being part of the complete blood count (CBC) measurement. This may be because the clinical practice at the time of the study observation period (2016-2018) did not require routine measurement of blood 
eosinophil counts to assess patients' eligibility for phenotype-guided biologic therapy. Previously published data from Russia (27) as well as the results of this study suggest that biologics were infrequently used to treat severe asthma in Russia, and so this may also partly explain the limited measurement of eosinophil counts observed in this study considering eosinophil counts are used to guide biologic therapy. Furthermore, approximately one-third of patients visited general/family practice physicians for the treatment of severe asthma. Since eosinophil counts are not routinely measured in general/family medicine, this may also explain the limited data on eosinophil counts.

Despite clinical significance implied by some authors, especially for uncontrolled asthma patients, IgE levels were not measured in most patients (22). FEV1 values in this study should be considered as moderately severe lung impairment (23). It was shown in one study that low FEV1 I may be a risk factor of future exacerbation of asthma (24).

The most common treatment prescribed in the last 12 months was controller/maintenance treatment (99.4\%). This is to be expected considering the study inclusion criteria - for patients to be included in the study, they must have been treated with high dose ICS plus a second controller (and/or systemic corticosteroids). The next most frequently used treatments were reliever treatment (96.8\%), and exacerbation treatment (SABA excluded) $(79.0 \%)$, and other medication $(77.8 \%)$. The use of SABA, corticosteroids, and oxygen as treatment for exacerbations complies with guidelines for the management of exacerbations (25). However, use of SAMA for treatment of exacerbations, as observed in this study, is unusual and does not follow management guidelines (26), but combinations of SABA and SAMA is recommended to use in severe asthma exacerbation by GINA. The high proportion of other unspecified exacerbation treatments is also of scientific interest; this warrants further investigation to elucidate the specific other exacerbation treatments used.

Use of anti-IgE was very low (2.9\%), the same was also reported for severe asthma patients in Russian Severe Asthma Registry (RSAR) (27). Biologics are recommended when they are available/affordable in cases of severe asthma where patients are prescribed with high dose ICS treatment and fulfil the criteria for residual Type 2 airway inflammation (28). Therefore, drug availability/affordability may partly explain the low use of biologics in Russia during the study.

Most patients experienced at least one exacerbation in the last 12 months which required an intervention. Rates of hospital admission and duration of in-hospital stay were notably high, which can reflect standard of care in Russia during the study period (2016-2018). ISAR data indicated 12-month admission rates of $26.8 \%(12)$. Similarly, results from a study $(n=3,619)$ conducted among asthmatic patients across five European countries (France, Germany, Italy, Spain, and UK, observation period: 2008) reported a hospitalization rate of $27.3 \%$ over a 6 -month (29).

The mean (SD) ACT score was 11.4 (4.7) and is corresponded to uncontrolled asthma. This mean score is in line with findings from other research; one study conducted in Brazil among severe asthmatic patients $(n=74)$ in an outpatient clinic reported a similar mean (SD) ACT score of 11.7 (4.5) (30). Moreover, disease course significantly affected patient's quality of life. 
Overall, the findings of this study suggest an unmet medical need among severe asthmatic patients in Russia. The majority of patients in the study sample used medium/high dose ICS/LABA (along with a second therapy). However, most patients had uncontrolled asthma, according to the ACT; and experienced at least one exacerbation in the past 12-months. In addition, most patients reported a reduction in the quality of their life due to their severe asthma.

\section{Conclusion}

The results of this study showed that alongside elevated eosinophil levels, most patients in the study sample had uncontrolled asthma, and most patients experienced at least one severe exacerbation within the past year. Additionally, most patients reported at least moderate limitations in their usual activities due to asthma. In line with these findings, healthcare resource use among patients was high. Most patients experienced at least one severe exacerbation during the last 12 months which required an intervention, some patients experienced two; and most patients experienced at least one exacerbation in the last 12 months which required hospitalization. Overall, the findings of this study suggest an unmet medical need among severe asthmatic patients. Although most patients used medium/high dose ICS/LABA (along with a second therapy), which is the preferred treatment option for uncontrolled asthma, most patients remained uncontrolled. This highlights a need for alternative or additional treatment options for severe asthma.

In recent years, new biological agents that block eosinophil specific interleukins (IL) such as anti-IL5 have become available (31). Research has shown that treatment with these new biologics result in a marked reduction in exacerbations and a significant improvement in $\mathrm{HRQ}$ oL $(10,32)$. To capitalize on the newly available biologics, it is important to diagnose severe eosinophilic asthma at an earliest convenience.

\section{Abbreviations}




\begin{tabular}{|c|c|}
\hline Abbreviation & Definition \\
\hline ACT & Asthma Control Test \\
\hline ANOVA & Analysis of variance \\
\hline ATS & American Thoracic Society \\
\hline $\mathrm{CBC}$ & Complete blood count \\
\hline COPD & Chronic obstructive pulmonary disease \\
\hline EQ-5D-5L & Five level EuroQol five-dimension \\
\hline ER & Emergency room \\
\hline ERS & European Respiratory Society \\
\hline FEV1 & Forced expiratory volume in first second \\
\hline FVC & Forced vital capacity \\
\hline GCP & Good clinical practice \\
\hline GINA & Global Initiative for Asthma \\
\hline GPP & Good pharmacoepidemiology practices \\
\hline HRQoL & Health-related quality of life \\
\hline ICF & Informed consent form \\
\hline $\mathrm{ICH}$ & $\begin{array}{l}\text { International Council for Harmonisation of Technical Requirements for } \\
\text { Pharmaceuticals for Human Use }\end{array}$ \\
\hline ICS & Inhaled corticosteroid \\
\hline $\lg E$ & Immunoglobulin E \\
\hline ISAR & International Severe Asthma Registry \\
\hline LABA & Long-acting $\beta$-agonists \\
\hline LEC & Local Ethic Committee \\
\hline LTRA & Leukotriene receptor agonist \\
\hline OCS & Oral corticosteroid \\
\hline RSAR & Russian Severe Asthma Registry \\
\hline SABA & Short-acting $\beta$-agonists \\
\hline SAMA & Short-acting muscarinic antagonist \\
\hline SCS & Systemic corticosteroid \\
\hline SD & Standard deviation \\
\hline
\end{tabular}




SIV Site initiation visit

VAS Visual analogue scale

\section{Declarations}

\section{Ethics approval and consent to participate}

This study was reviewed and approved by the Local Ethics Committee. The study was conducted in accordance with good pharmacoepidemiology practice (GPP) and International Council for Harmonisation of Technical Requirements for Pharmaceuticals for Human Use (ICH) good clinical practice (GCP). Data protection and privacy regulations were strictly observed in collecting, forwarding, processing, and storing patient data. All applicable patient privacy requirements, and ethical principles outlined in the Declaration of Helsinki 2008 were followed.

Informed consent form (ICF) was signed by patients included in Phase II. Medical record data collected during Phase I was considered secondary and did not require an ICF signature.

The study was reviewed and approved by Local Ethic Committees in Russia ( LEC at State Budgetary Health Institution "Regional Clinical Hospital \#3" Chelyabinsk, LEC at Regional State Budgetary Institution of Healthcare "City Hospital \#5" Barnaul, LEC at State Budgetary Institution of higher Professional Education "Krasnoyarsk State Medical University n.a. professor Voyno-Yasenetskogo", LEC at Irkutsk State Medical Academy of Postgraduate Education - branch of Federal State Budgetary Educational Institution of additional professional education "Russian Medical Academy of Continuously Professional Education", LEC at State Budgetary Healthcare Institution of Novosibirsk region "State Regional Clinical Hospital of Novosibirsk", LEC at "Outpatient clinic \#2" Yaroslalv, LEC at State Autonomous Healthcare Institution "Clinical Hospital \#2"Yaroslavl, LEC at State Autonomous Healthcare Institution of Yaroslavl Region "Clinical Hospital of Emergency Care named after N.V. Solovyev" Yaroslavl, LEC at State Budgetary Clinical Institution of Healthcare of Yaroslavl Region "City Clinical Hospital n.a. Semashko N.A" Yaroslavl, LEC at Regional State Budgetary Healthcare Institution "Clinical Hospital \#1" Smolensk, LEC at Federal State Budgetary Educational Institution of Higher Professional Education "North-Western State Medical University n.a. Mechnikov I.I." St. Petersburg.

\section{Consent for publication}

Not applicable.

\section{Availability of data and material}

The datasets used and/or analysed during the current study are available from the corresponding author on reasonable request.

\section{Competing interests}


A. E., G. I. report grants from GlaxoSmithKline, during the conduct of the study.

L. T., J. M., S. F., R. A., T. E. are GSK employees and shareholders.

\section{Funding}

The study was funded by GlaxoSmithKline (GSK Study Number 207102). GSK was involved in the study design, collection, analysis, and interpretation of the data, in the writing of the report, and in the decision to submit the article for publication.

\section{Author's contributions}

All listed authors meet the criteria for authorship set forth by the International Committee for Medical Journal Editors.

Z. A., O. K., T. E. provided support in the study concept and protocol development and data analysis and interpretation.

A. E., G. I. provided support in the study concept and acquisition of data.

L. T., J. M., S. F., R. A. provided support in data analysis and interpretation.

All authors took active part in this study design, acquisition of data, analysis, and interpretation of the study data. The authors contributed to manuscript review, applying their clinical, epidemiology, and study design expertise and take responsibility for the integrity of the data and the accuracy of the data analysis.

All authors participated in critical revisions of the manuscript and have approved the article for publication.

\section{Acknowledgements}

We thank all investigators for their contribution to the study, allowing the clinical epidemiology research to happen with a high level of integrity and the contract research organisation, IQVIA, which was funded by GSK, performing the study organisation and conduct.

Editorial support in the form of draft outline, editorial suggestions to draft versions of this paper, collating author comments, assembling tables and figures, referencing, and copyediting was provided by Aleksander Solodovnikov at Statandocs and was funded by GSK.

\section{References}

1. de Groot JC, Ten Brinke A, Bel EHD. Management of the patient with eosinophilic asthma: a new era begins. ERJ Open Res. 2015 May;1(1):00024-2015. 
2. Neffen H, Fritscher C, Schacht FC, Levy G, Chiarella P, Soriano JB, et al. Asthma control in Latin America: the Asthma Insights and Reality in Latin America (AIRLA) survey. Rev Panam Salud Publica. 2005 Mar;17(3):191-7.

3. Bavbek S, Misirligil Z. A breath for health: An exploratory study in severe asthma patients in Turkey. Allergy. 2008 Oct 1;63:1218-27.

4. Chung KF, Wenzel SE, Brozek JL, Bush A, Castro M, Sterk PJ, et al. International ERS/ATS guidelines on definition, evaluation and treatment of severe asthma. European Respiratory Journal. 2014 Feb $1 ; 43(2): 343-73$.

5. Franco R, Nascimento HF, Cruz AA, Santos AC, Souza-Machado C, Ponte EV, et al. The economic impact of severe asthma to low-income families. Allergy. 2009 Mar;64(3):478-83.

6. Cruz AA, Bousquet PJ. The unbearable cost of severe asthma in underprivileged populations. Allergy. 2009 Mar;64(3):319-21.

7. Polosa R. An overview of chronic severe asthma. Intern Med J. 2008 Mar;38(3):190-8.

8. Moore WC, Meyers DA, Wenzel SE, Teague WG, Li H, Li X, et al. Identification of asthma phenotypes using cluster analysis in the Severe Asthma Research Program. Am J Respir Crit Care Med. 2010 Feb 15;181(4):315-23.

9. Flood-Page PT, Menzies-Gow AN, Kay AB, Robinson DS. Eosinophil's role remains uncertain as antiinterleukin-5 only partially depletes numbers in asthmatic airway. Am J Respir Crit Care Med. 2003 Jan 15;167(2):199-204.

10. Ortega HG, Liu MC, Pavord ID, Brusselle GG, FitzGerald JM, Chetta A, et al. Mepolizumab treatment in patients with severe eosinophilic asthma. N Engl J Med. 2014 Sep 25;371(13):1198-207.

11. Melgert BN, Ray A, Hylkema MN, Timens W, Postma DS. Are there reasons why adult asthma is more common in females? Curr Allergy Asthma Rep. 2007 May;7(2):143-50.

12. Wang E, Wechsler ME, Tran TN, Heaney LG, Jones RC, Menzies-Gow AN, et al. Characterization of Severe Asthma Worldwide: Data From the International Severe Asthma Registry. Chest. 2020 Apr;157(4):790-804.

13. Su X, Ren Y, Li M, Zhao X, Kong L, Kang J. Prevalence of Comorbidities in Asthma and Nonasthma Patients: A Meta-analysis. Medicine (Baltimore). 2016 May;95(22):e3459.

14. Kankaanranta H, Kauppi P, Tuomisto LE, Ilmarinen P. Emerging Comorbidities in Adult Asthma: Risks, Clinical Associations, and Mechanisms. Mediators Inflamm. 2016;2016:3690628.

15. Black MH, Anderson A, Bell RA, Dabelea D, Pihoker C, Saydah S, et al. Prevalence of asthma and its association with glycemic control among youth with diabetes. Pediatrics. 2011 Oct;128(4):e839-847.

16. Tai A, Tran H, Roberts M, Clarke N, Wilson J, Robertson CF. The association between childhood asthma and adult chronic obstructive pulmonary disease. Thorax. 2014 Sep;69(9):805-10.

17. Mirabelli MC, Beavers SF, Chatterjee AB, Moorman JE. Age at asthma onset and subsequent asthma outcomes among adults with active asthma. Respir Med. 2013 Dec;107(12):1829-36. 
18. Zein JG, Dweik RA, Comhair SA, Bleecker ER, Moore WC, Peters SP, et al. Asthma Is More Severe in Older Adults. PLoS One. 2015;10(7):e0133490.

19. Szefler SJ, Raphiou I, Zeiger RS, Stempel D, Kral K, Pascoe S. Seasonal variation in asthma exacerbations in the AUSTRI and VESTRI studies. ERJ Open Research [Internet]. 2019 Apr 1 [cited 2021 Jul 2];5(2). Available from: https://openres.ersjournals.com/content/5/2/00153-2018

20. Singh AM, Busse WW. Asthma exacerbations · 2: Aetiology. Thorax. 2006 Sep;61(9):809-16.

21. Tiotiu A. Biomarkers in asthma: state of the art. Asthma Research and Practice. 2018 Dec 21;4(1):10.

22. Mahboub et al. Recommendations for severe asthma management from a Gulf Cooperation Council expert panel aiming to optimize regional clinical practice. Medical Research Archives. 7(12).

23. Pellegrino R, Viegi G, Brusasco V, Crapo RO, Burgos F, Casaburi R, et al. Interpretative strategies for lung function tests. European Respiratory Journal. 2005 Nov 1;26(5):948-68.

24. Quezada WA, Kwak ES, Reibman J, Rogers L, Mastronarde J, Teague WG, et al. Predictors of asthma exacerbation among patients with poorly controlled asthma despite inhaled corticosteroid treatment. Annals of allergy, asthma \& immunology: official publication of the American College of Allergy, Asthma, \& Immunology. 2016 Feb;116(2):112.

25. Asthma NAE and PP Third Expert Panel on the Diagnosis and Management of. Expert Panel Report 3: Guidelines for the Diagnosis and Management of Asthma. National Heart, Lung, and Blood Institute (US); 2007.

26. Lipworth BJ. Emerging role of long acting muscarinic antagonists for asthma. Br J Clin Pharmacol. 2014 Jan;77(1):55-62.

27. Nenasheva N, Belevsky A. Characteristics of Patients with Severe Asthma in the Russian Federationthe Russian Severe Asthma Registry. In: A32 ASTHMA: CLINICAL STUDIES II [Internet]. American Thoracic Society; 2019 [cited 2021 Jul 2]. p. A1337-A1337. (American Thoracic Society International Conference Abstracts). Available from: https://www.atsjournals.org/doi/abs/10.1164/ajrccmconference.2019.199.1_MeetingAbstracts.A1337

28. GINA. Difficult-to-treat and severe asthma in adoloscent and adult patients: Diagnosis and management. 2018.

29. Demoly P, Gueron B, Annunziata K, Adamek L, Walters RD. Update on asthma control in five European countries: results of a 2008 survey. Eur Respir Rev. 2010 Jun;19(116):150-7.

30. de Carvalho-Pinto RM, Cukier A, Angelini L, Antonangelo L, Mauad T, Dolhnikoff M, et al. Clinical characteristics and possible phenotypes of an adult severe asthma population. Respir Med. 2012 Jan;106(1):47-56.

31. Hilvering B, Xue L, Pavord ID. Evidence for the efficacy and safety of anti-interleukin-5 treatment in the management of refractory eosinophilic asthma. Ther Adv Respir Dis. 2015 Aug;9(4):135-45.

32. Bel EH, Wenzel SE, Thompson PJ, Prazma CM, Keene ON, Yancey SW, et al. Oral glucocorticoidsparing effect of mepolizumab in eosinophilic asthma. N Engl J Med. 2014 Sep 25;371(13):118997. 
Figures

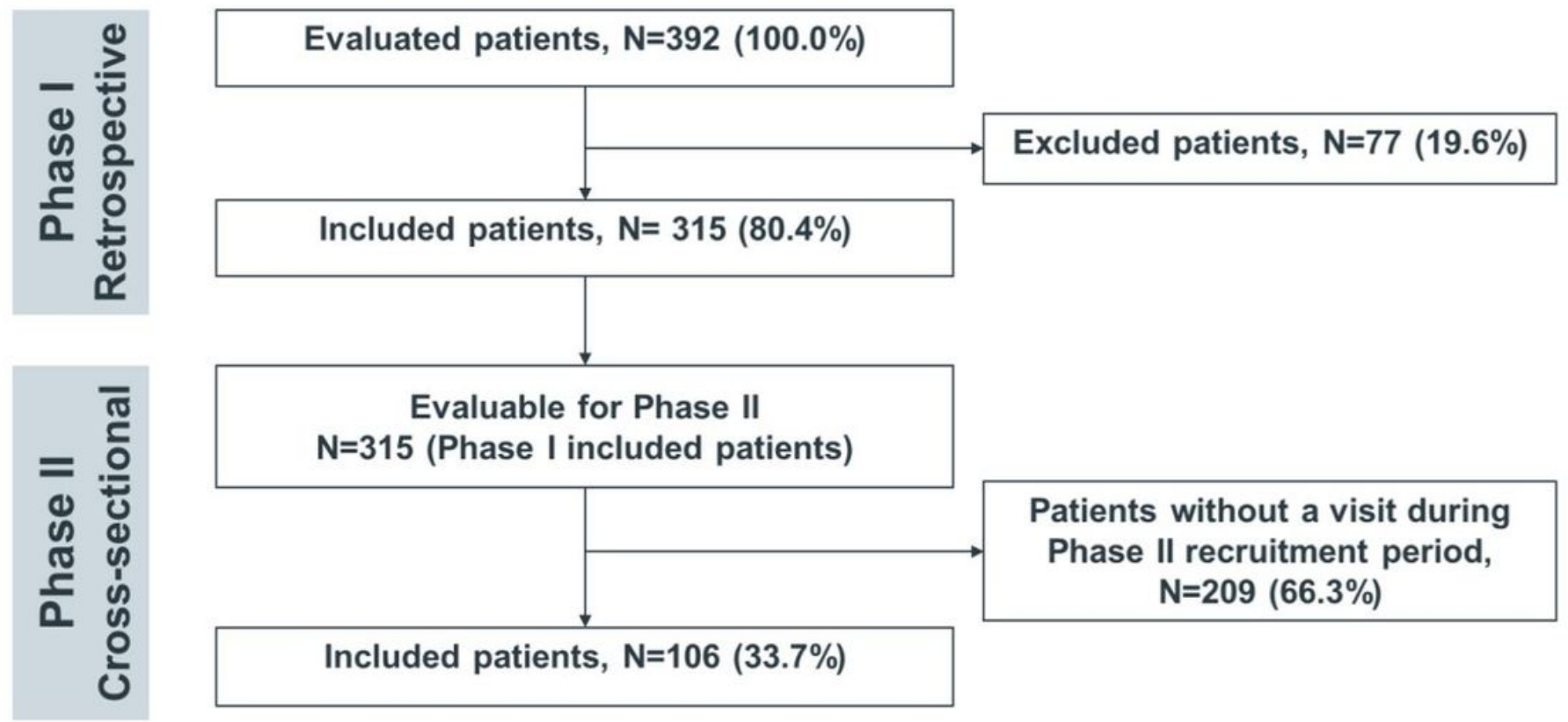

Figure 1

Patient flow chart 


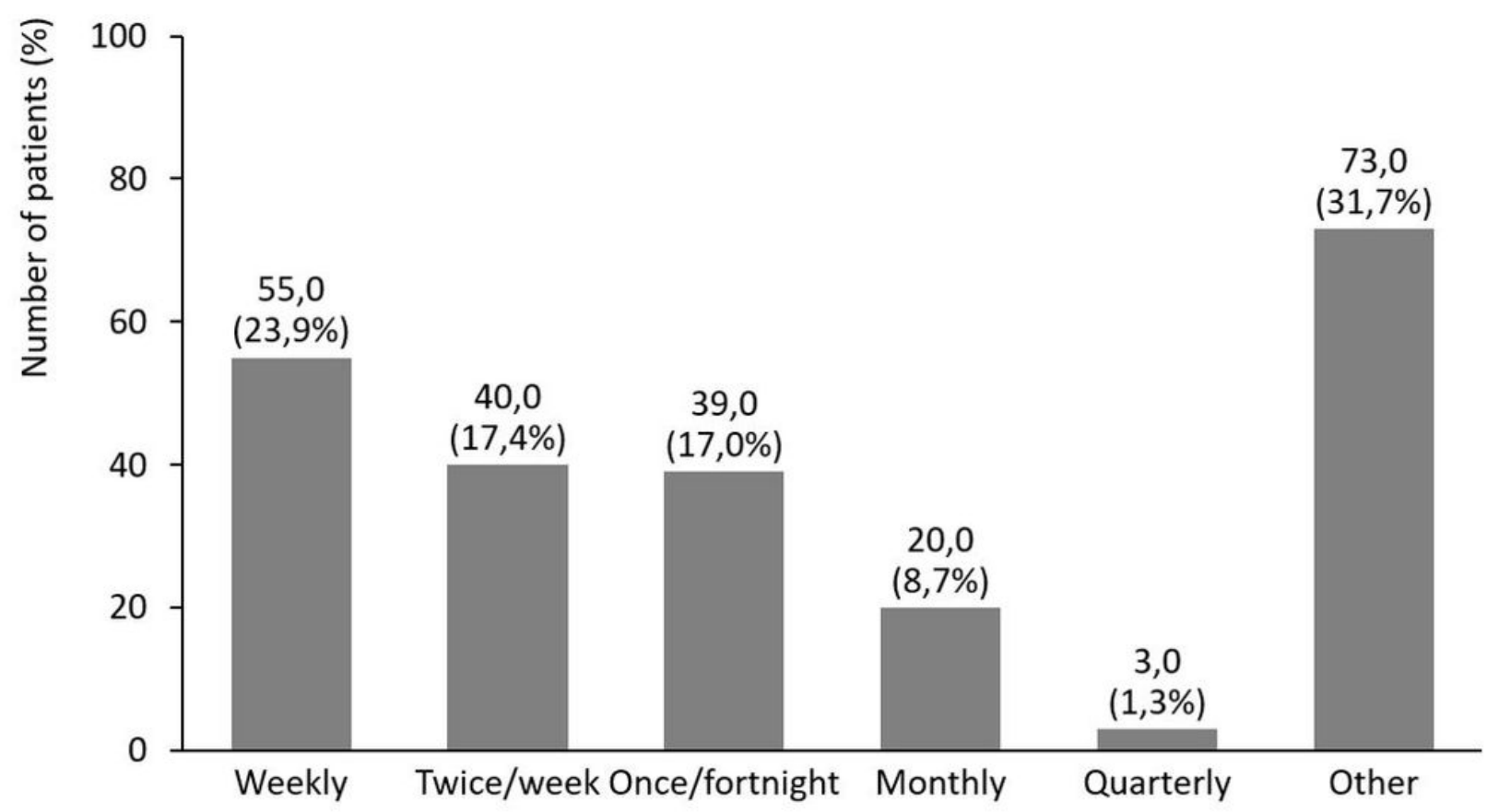

Figure 2

Frequency of nighttime awakenings due to severe asthma during 12 months prior to data entry

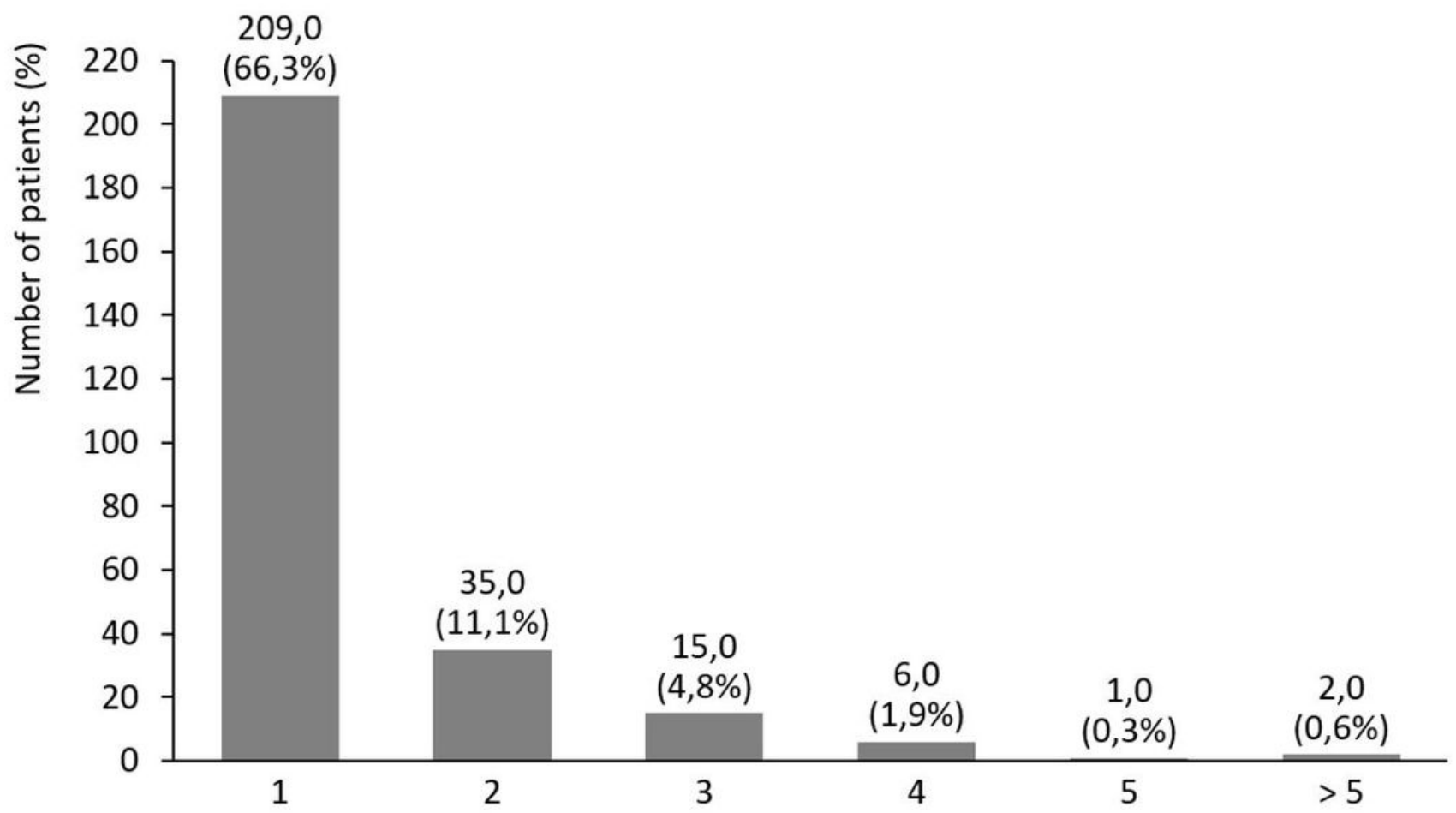


Figure 3

Frequency of exacerbations during the 12 months prior to data entry

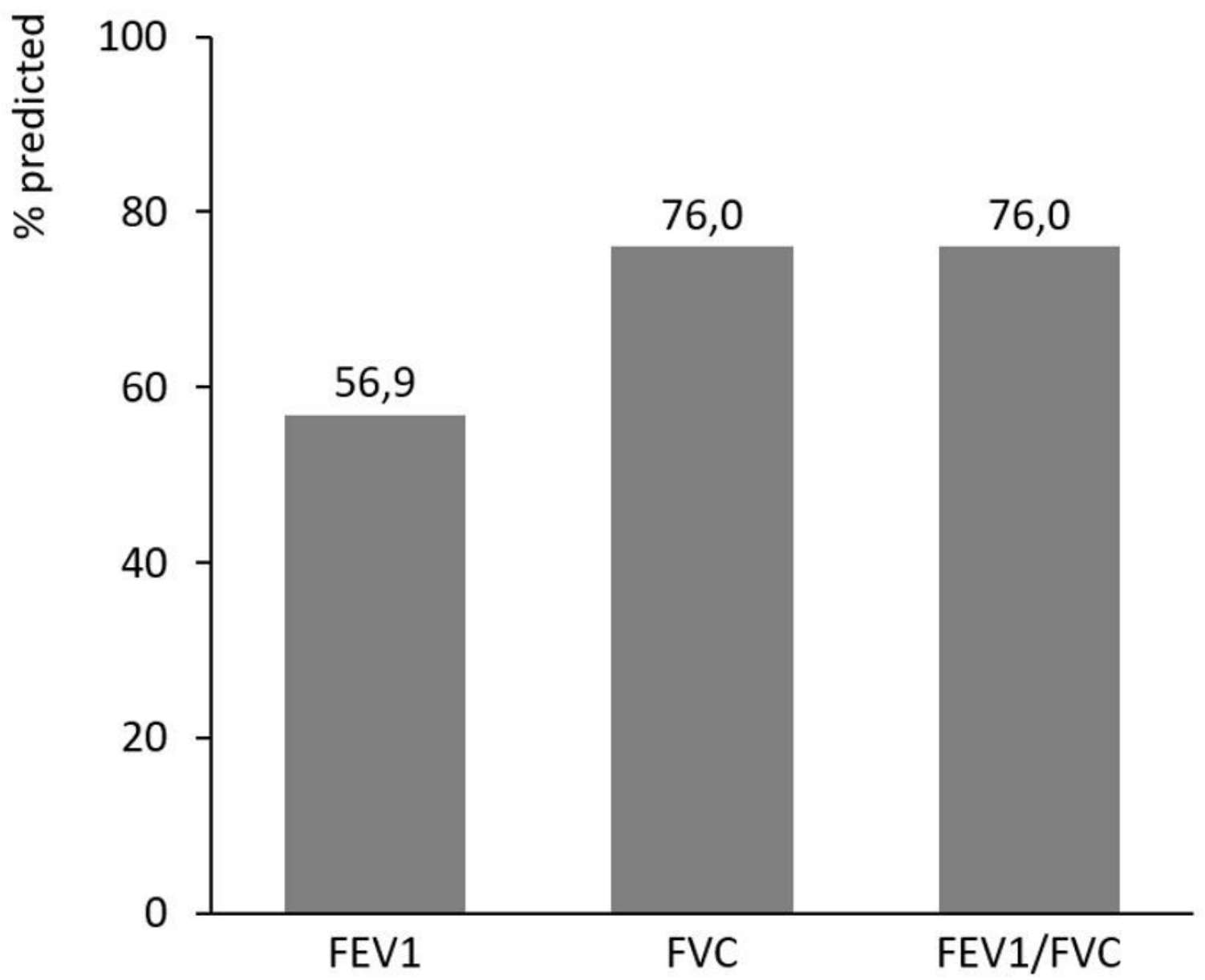

Figure 4

Last available spirometry measurement 